REVISTA DE LA UNIVERSIDAD DEL AZUAY

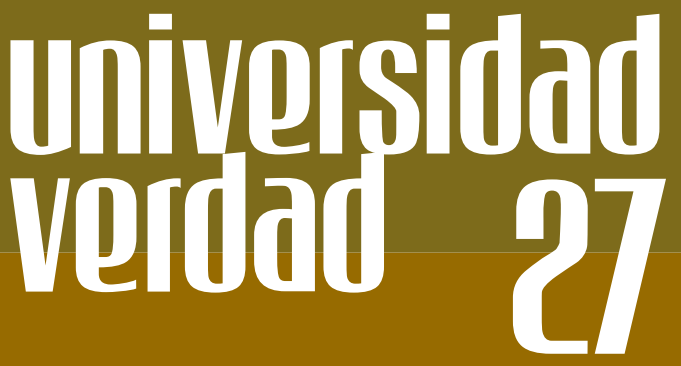

UNIVERSIDAD

DEL AZUAY

\title{
LA ANTROPOLOGIA CULTURAL: EL HUMANISMO DEL SIGLO XXI
}

Claudio Malo González Doctor en Filosofia 
Las humanidades no clásicas han intentado extender el campo de acción , y la etnología, desde este punto de vista, , no ha hecho sino prolongar hasta sus límites últimos el tipo de curiosidad y actitud mental cuya orientación no se ha modificado desde el Renacimiento, y que solo en la observación y reflexión etnológicas encuentra infinito definitivo cumplimiento. De este modo, la etnología aparece como la forma reciente de humanismo, adaptando éste a las condiciones del mundo finito en que se ha convertido el globo terrestre en el siglo XX; siglo a partir del cual de hecho, $y$ no solo de derecho, como antes, nada humano puede ser ajeno al hombre.

Claude Lèvi-Straus ${ }^{1}$

\section{Introducción}

Platón afirmó que la curiosidad es el principal motor de la Filosofía que en aquellos tiempos incluía a todas las ciencias. Si a diferencia de los demás integrantes del reino animal la realidad física y humana nos plantea interrogantes con el consiguiente deseo de despejar esas incógnitas, las respuestas acumuladas y ordenadas sistemáticamente, tienden a situarnos en un entorno significativo y a encontrar algún sentido a nuestra existencia. Todos los pueblos del mundo así han actuado y, sobrepasando respuestas individuales a problemas personales, se han elaborado sistemas más o menos coherentes aceptados por la colectividad a cerca de sus orígenes y destinos colectivos.

La curiosidad va más allá de respuestas a problemas concretos por el puro afán de saber, con frecuencia están acompañadas de actitudes y formas de comportamiento que debemos asumir frente a la realidad circundante; cómo debemos enfrentarnos a los fenómenos físicos amigables u hostiles para adaptarnos a sus posibilidades 
y limitaciones u obtener mayor provecho de los que nos ofrecen. Un paso adelante a esta incitación de la curiosidad supone intentar respuestas a interrogantes que van más allá de las ofertas y negaciones de los fenómenos naturales, cuando nos preguntamos -no importa si en términos elementales o complicados- cual es la razón de ser de nuestra vida, de donde provenimos como colectividad y que finalidad tiene nuestra existencia.

Cuando Aristóteles calificó al hombre de "animal político", no se limitó a hacer referencia al grado de interés que todo ser humano tiene en la gestión pública. Afirmó que por naturaleza la existencia humana tiene sentido en cuanto forma parte de una colectividad, la "polis", como los griegos entendían a esos conglomerados organizados que afianzaban la identidad y el compromiso de sus integrantes, a la vez que enfatizaban las diferencias con otros grupos similares o más amplios.

Dotados como estamos de siquismo superior, podemos mediante la memoria retener en nuestras mentes acontecimientos del pasado rompiendo las barreras generacionales y aprovechar las experiencias positivas de lo hecho por nosotros y quienes nos antecedieron en el tiempo; podemos a la vez, con razonable credibilidad, prever lo que ocurrirá en el futuro y actuar en el presente esperando que, transcurrido algún tiempo, se produzcan efectos deseados y anticipados. El sentido de temporalidad es parte de nuestro ser, no somos meros relojes que fría e implacablemente marcan el transcurso de las horas y los días; nuestras capacidades superiores -en relación con los demás integrantes del reino animaly nuestra libertad nos permiten tomar decisiones en nuestras vidas; "hacernos en el tiempo" en el sentido orteguiano de esta afirmación.

Somos creativos, somos creadores. Biológicamente hemos llegado a ser la culminación del proceso de evolución de las especies partiendo de elementales formas de vida, pero la evolución de los conglomerados humanos en su múltiple diversidad y proyección está más allá de los mecanismos científico-biológicos; de ser receptivo se convierte en actor y protagonista de la evolución pues a sus ideas, 
sentimientos y acciones se deben los cambios en las sociedades, los avances tecnológicos, las creencias a cerca de la realidad material y no material, las teorías filosóficas, los rituales y ceremoniales vinculados a las religiones, las normas que nacen de las concepciones de bien y mal. A diferencia de las demás especies animales que organizan sus vidas mediante el instinto que nace programado en cada individuo, los seres humanos las organizamos mediante un complejo de ideas y creencias que se traducen en pautas de conducta, surgiendo lo que en Antropología se denomina cultura que cambia con el tiempo y se caracteriza por su diversidad en los múltiples espacios físicos y conglomerados sociales.

\section{En torno al humanismo}

Las reflexiones a cerca de este concepto y los planteamientos que sobre él se han hecho, se circunscriben al mundo Occidental. Existen ideas y creencias que con legitimidad y plenitud merecen el apelativo de humanistas en civilizaciones no occidentales, pero las limitaciones de este trabajo no posibilitan salirnos de los límites de Occidente.

Como muchos términos de las disciplinas sociales, humanismo se caracteriza por la abundancia de interpretaciones que el concepto -o conceptos- que porta posibilita. En el Renacimiento, cuando resurge con vigor el estudio del pensamiento y realizaciones estéticas de la Grecia Clásica, se habla de humanismo haciendo referencia a las grandes posibilidades de realización del ser humano, como contraposición a la posición medieval que centraba en Dios y la relación que el hombre debía tener con él la razón de ser de la humanidad y la organización y proyección de los quehaceres sociales. En Filosofía, es claro que humanismo supone que el ser humano es el sujeto y último fin del filosofar.

El presocrático Protágoras de Abdera afirmó que "El hombre es la medida de todas las cosas, de las que son en cuanto son y de las que no son en cuanto no son" declarando que la realidad externa 
depende de la existencia humana. El "Conócete a ti mismo de Sócrates" como meta esencial de la sabiduría sintetiza la apuesta griega por el ser humano. Si consideramos que la Filosofía, más que un sistema ordenado de especulación a cerca de los grandes principios y causas de la realidad, es y debe ser una forma de vida, como pensaban los griegos, es lógico que el ser humano sea el eje del filosofar. Dentro de este contexto se puede afirmar que un enfoque coherente de la cultura -como creación humana- debe proyectarse hacia la mejor de las posibles realizaciones de su creador y fin último: el hombre.

Pierre Hadot, en su obra "Philosophy as a Way of Life en 1995 escribió: "La Filosofía antigua proponía a la humanidad un arte de vivir, en cambio la filosofía moderna se muestra sobre todo como la construcción de una jerigonza reservada a los especialistas"

En el mundo heleno la idea más generalizada era que el ser humano era un componente de la naturaleza, privilegiado en cierto sentido, pero parte de este gran entorno. Uno de los principios más difundidos era: "vive conforme a la naturaleza", es decir acóplate a sus leyes y sistemas de ordenamiento y no pretendas aislarte 0 separarte, peor aún violentarla. No habiéndose producido aún el desgajamiento de las ciencias del árbol de la Filosofía, todas las áreas del pensamiento humano estaban incluidas en esta disciplina sinónimo de sabiduría. Los más grandes representantes de la Filosofía Griega: Sócrates, Platón y Aristóteles dieron especial importancia a la Etica y la Política como respuestas a los interrogantes a cerca de la vida individual y colectiva. Posteriormente, escuelas como las de los Estoicos y Epicúreos, centraron en la Etica -es decir en los mejores de los posibles modelos de vida del hombre- sus esfuerzos filosóficos. Los discípulos de los grandes filósofos, no solo se juntaban a ellos para departir, aprender y desarrollar su intelecto sino también, y quizás principalmente, en busca de algún tipo de orientación en sus vidas. ${ }^{2}$

En la Edad Media, la Filosofía Cristiana pretende esclarecer mediante la razón lo que Dios reveló. También el ser humano es el 
centro de los esfuerzos filosóficos. El tiempo que pasamos en este mundo es un tránsito hacia otra vida que se inicia con la muerte, en la que se salvará o condenará definitivamente. Dotado como está de libertad, su destino final depende de cómo se comporte en la tierra siendo, en última instancia, responsable de su suerte definitiva. En el humanismo cristiano el sentido del mundo se centra en como deben estar organizadas la sociedad y la conducta individual para que sus integrantes se realicen de la mejor manera posible logrando la salvación eterna y evitando la condenación. Dios es el centro del universo y el hombre, como la manifestación más completa y querida de su creación, tiene que organizar su vida en función de El. Si hablamos de un humanismo medieval, sería teocéntrico y su fórmula: vive conforme Dios lo quiere.

El Racionalismo y el Empirismo en los siglos XVII y XVIII, replantean lo que consideramos humanismo. Partiendo de la frase "pienso luego existo"; como resultado de su duda metódica, Descartes establece un distanciamiento entre la naturaleza y la razón, entre las ideas -sobre todo las innatas- y el mundo de las cosas. Puesto que el ser humano puede razonar, lo que cuenta es aprehender esa realidad externa y analizarla mediante las ideas no solo para comprenderla mejor, sino para retornar a ella y obtener el mayor provecho posible. Los empiristas (partiendo del planteamiento de John Locke en el sentido de que al nacer los seres humanos son como un papel en blanco que se llena a lo largo del tiempo mediante las experiencias que tengamos con la realidad externa), establecen la misma posición de aislamiento al entender al hombres como separado y diferente de la naturaleza, como dotado de capacidad para conocer sus más profundos secretos a través de la ciencia y para modificar el entorno natural de la manera más eficiente posible mediante la técnica. ${ }^{3}$

La realización más exitosa del ser humano, según estos planteamientos, depende de la mejor manera en que use su capacidad de razonar (dando mayor importancia la razón o la experiencia es, para este propósito, secundario). La razón todo lo puede y de su uso correcto y sistemático que supere posiciones "obscurantistas" depende el éxito individual y colectivo. Partiendo de una concepción 
mecanicista de la realidad externa Laplace considera que si mediante la razón podríamos conocer un momento dado la posición y velocidad de todas las partículas que forman la realidad, estaríamos en capacidad de predecir con precisión lo que ocurra en el futuro. El optimismo racionalista no tiene límites. Las limitaciones y fracasos se deben a que en el pasado no ha habido un empeño consciente por explotar esta característica que nos separa de los otros integrantes del reino animal: la razón, pero descubierto este guardado secreto, todos los problemas se solucionarán con el tiempo. Mientras más sepamos a través de la razón y la experiencia, más cercanos estaremos a la plena realización de nuestra condición humana y habremos cumplido nuestro cometido en la tierra. El principio sería: vive conforme a la razón.

El idealismo que se desarrolló en Alemania, plantea nuevas concepciones de la realidad y del ser humano como integrante de ella. Al predominio del ser en la interpretación, el idealismo propone el predominio del devenir. El tiempo cobra especial importancia, pero no como un escenario pasivo en el que se dan las cosas, sino como un proceso de cambio. En el caso del hombre, dentro de esta dimensión, se hace en el tiempo. A diferencia de un determinismo consecuencia de la estructura mecanicista, en el idealismo se resalta el predominio de la libertad que posibilita mediante la dinámica del cambio el pleno desarrollo de la creatividad. En última instancia, toda práctica de la libertad supone alguna forma de creación, pues el resultado de una decisión implica la opción por algo nuevo que avanza en el tiempo sin responder necesariamente a un predeterminismo ya existente.

En el idealismo, si hablamos de prioridades en la conducta humana, la voluntad desplaza a la razón. La razón conoce y analiza, la voluntad actúa. Si lo que prima es el devenir y el cambio es esta facultad la que impulsa las nuevas y casi siempre transitorias realizaciones. Pero no se trata de una voluntad sin brújula y carente de orden; el movimiento, el devenir, el cambio se dan estructurados por un finalismo, algo así como una meta que pasa por una serie de etapas. 
Del idealismo surgieron algunos movimientos que buscaban una interpretación y una proyección de la realidad humana global, siendo el que más trascendencia ha tenido el romanticismo. Como una reacción contra el racionalismo que exaltaba excesivamente a la razón, el romanticismo entiende la realidad social como algo en la que predomina la voluntad y la vida afectiva. La creatividad inherente a la condición humana deja de ser un minucioso y frío trabajo de la razón y se convierte en una cálida manifestación de los sentimientos y la voluntad que sustituye, en cierto sentido, la planificación de la razón. En héroes literarios del romanticismo el poder del sentimiento puede más que los meticulosos análisis racional Poco se miden las consecuencias pues el sentimiento es explosivo. La razón puede explicar el porqué de hechos que ya sucedieron, pero en las acciones la pasión avasalla a la reflexión.

Si hablamos de un humanismo idealista, se amplía la dimensión humana al hacer de la voluntad y los sentimientos componentes integrales de la misma, al sustituir su predeterminación mecanicista por el permanente ejercicio de la libertad que de hechuras nos transforma en hacedores de nuestro ser total. Cuando el romanticismo habla del "volkgeist" anuncia la creatividad como una expresión colectiva que arranca de las manifestaciones de las comunidades y no de genialidades individuales.

José Ortega y Gasset, en el siglo XX plantea para la comprensión del ser humano el concepto "circunstancia". Yo soy yo y mi circunstancia, es una frase en la que en buena medida se sintetiza su pensamiento en este aspecto. Aplicado a la historia, las variaciones que se dan en el tiempo hacen que los esfuerzos para la comprensión del pasado tienen que tomar en consideración las circunstancias en los que los hechos se dieron pues sus actores necesariamente tenían que comportarse inmersos y, en cierto sentido, condicionados por ellas. La tergiversación -voluntaria o involuntaria- de los hechos históricos se debe a la tendencia a emitir juicios de valor e intentar explicaciones partiendo de las circunstancias que actualmente vivimos. 
Es legítimo usar el concepto circunstancia para aproximarnos a la comprensión de personas y grupos que, coexistiendo en un mismo tiempo, han desarrollado deferentes ideas y creencias a cerca de la realidad material y no material, jerarquizan los valores de manera distinta y se plantean otras metas en la vida. Para un cristiano protestante que funciona dentro de parámetros éticos según lo interpretó Max Weber y que da importancia al éxito económico como consecuencia del trabajo, el comportamiento de una persona que practica con devoción la religión Hindú puede parecer incoherente, pero las circunstancias, en este caso religiosas, son diferentes.

La circunstancia no es hechura de cada persona, está vigente como consecuencia del desarrollo cultural de los pueblos y cada quien nace y se realiza en medio de ella. Una visión humanista dentro de este contexto nos lleva a aceptar que una de las peculiaridades de la humanidad es la diferencia en cuanto a cultura y que una comprensión del hombre como centro de la realidad y objeto del filosofar tiene que partir de esta diferencia. Si como decía Aristóteles el ser humano por naturaleza busca la felicidad, cada quien lo hace partiendo de patrones distintos, jugando un papel fundamental en este aspecto la colectividad y la época en medio de las que nació, pues cada colectividad, modelada dentro de una estructura de valores y creencias, cambia con el tiempo.

\section{El ser humano y la cultura}

Partiendo de la palabra latina, colere, el sentido predominante del término cultura se refiere al conjunto de conocimientos, ideas, gustos y modos de actuar que poseen algunas minorías de personas que han tenido la posibilidad de educarse de acuerdo con pautas admitidas como superiores, sea en el mundo, sea en comunidades menores. Aceptando este concepto es lícito hablar en las sociedades de una minoría culta y la mayoría inculta integradas por aquellos que se cultivaron y los que no lo hicieron.

En 1871 Edward Tylor publica su obra "Primitive Culture", 
acontecimiento que para un buen número de personas marca el inicio de la Antropología Cultural como ciencia; en esta obra propone la siguiente definición de cultura: "Es un conjunto complejo que incluye el conocimiento, las creencias, el arte, la moral, la ley, la costumbre y cualquier otro hábito y aptitud que ha adquirido el hombre como miembro de la sociedad".

Al concepto tradicional de cultura, como cultivo, se propone otro como definitorio de las comunidades humanas que, capaces de organizar su conducta mediante pautas e ideas por ellas creadas, elaboran complejos materiales y no materiales a lo largo de los años, Con este enfoque la cultura es un elemento que diferencia al ser humano de los demás integrantes del reino animal, no siendo correcto hablar de pueblos o personas cultas e incultas y siendo evidente la existencia de diferentes culturas. Los dos significados de cultura han coexistido generando confusiones en las aproximaciones a la realidad humana colectiva. El Diccionario de la Real Academia de la Lengua en su edición de 1980 define cultura como "Resultado o efecto de cultivar los conocimientos humanos y de afinarse por medio del ejercicio de las facultades intelectuales del hombre". En su edición del año 2001 añade otra definición: "Conjunto de modos de vida y costumbres, conocimientos y grado de desarrollo artístico, científico e industrial en una época, grupo social etc." Si consideramos que este diccionario recoge el sentido más difundido que se da a las palabras avalado por el cuerpo colegiado que tiene máxima autoridad en la corrección del idioma, la incorporación de esta segunda definición con orientación antropológica muestra el avance que ha experimentado en veinte años.

El Antropólogo senegalés, que por veinte años desempeñó la Secretaria General de la Unesco, Amadou Mahtar M'Bow definió cultura: "Es a la vez aquello que una comunidad ha creado y lo que ha llegado a ser gracias a esa creación, lo que ha producido en todos los dominios en los que ejerce su creatividad y el conjunto de rasgos materiales y espirituales que, a lo largo de ese proceso han llegado a modelar su identidad y distinguirla de las otras". 
Muchas son las definiciones de cultura responden a las orientaciones y enfoques de quienes las hicieron, enfatizando en alguno de sus múltiples componentes. En esencia hay dos ideas básicas presentes: que es producto de la creación colectiva humana y que, siendo múltiples y diferentes, cada una de ellas tiene un conjunto de rasgos que la hacen distinta de las otras, surgiendo el término "identidad" en nuestros días tan usado y con frecuencia poco bien interpretado. Cada cultura es el resultado de la creación de una colectividad que la conforma a lo largo del tiempo. Con un criterio historicista podemos hablar de múltiples culturas haciendo referencia a las diferencias que en un mismo conglomerado humano se han dado a lo largo de los años en las distintas etapas históricas, pero podemos también entender estos cambios en el tiempo como procesos propios de la misma cultura. A riesgo de no ser afortunado en el símil, en una persona que ha vivido decenas de años se pueden encontrar diferencias en su ser y actuar, pero se trata de la misma.

Ninguna cultura aparece plenamente hecha, se hace a lo largo del tiempo experimentando múltiples cambios propios de la creatividad humana, procediendo en unos casos de diferentes respuestas que desde el interior se dan a problemas viejos o respuestas que se dan a nuevos y no previstos. En la mayoría de los casos estos cambios se originan en la incorporación de rasgos de otras culturas con las que se pone en contacto. Se habla de que, como en la vida humana, las culturas siguen una serie de etapas que se inician con su aparición y que desaparecen, lo que varía sustancialmente es la dimensión tiempo que supera muchas generaciones. Los cambios de las culturas no implican permanentes desapariciones y apariciones, ya que la permanencia de un núcleo de componentes, los más fuertes y definitorios, mantienen la identidad pese a las modificaciones.

Siendo la dimensión temporal propia de la Historia, la Antropología Cultural se empeña en comprender las diferencias existentes entre las múltiples culturas que en un mismo tiempo se dan en el mundo, superando la tendencia etnocéntrica que nos lleva a interpretar y enjuiciar los patrones de los otros conglomerados humanos con aquellos de los que yo formo parte lo que, de entrada, lleva a una 
errónea comprensión de lo otro.

\section{Cultura y persona}

Desde otro ángulo, si partimos del supuesto de que el ser humano tiene la capacidad de hacerse a lo largo del tiempo, esta posibilidad no es total y absoluta sino que está condicionada por una serie de factores como la época en que se vive. Arriesgado sería afirmar que si Julio César hubiera nacido en el siglo XX habría tenido un desempeño y logrado celebridad similares a las que alcanzó en su tiempo. Sin sostener un determinismo cultural, es evidente que influye en la conformación de la personalidad. Dentro de este contexto, si con seriedad queremos entender a otro, no podemos prescindir del entorno cultural en el que se desarrolló y tratar de comprender la cultura en la que se hizo. Sin emitir juicio de valor sobre la responsabilidad atribuida a Ben Laden en la destrucción de las torres gemelas, cualquier intento para entender este hecho, tiene que partir de una somera comprensión de la civilización islámica en la que, con una posición fundamentalista, justifica sus acciones.

Sin pretender una definición, podemos intentar una comprensión más amplia de lo que es una persona. Más allá de sus peculiaridades biológicas y de su siquismo superior que le permite una serie de modos de comportamiento al que los demás integrantes del reino animal no tienen acceso, una persona es en buena medida lo que la cultura en la que se desarrolló le ha hecho. Desde los inicios, en virtud del proceso de endoculturación, cada uno de nosotros incorporamos a nuestro ser una serie de ideas a cerca de la realidad y de actitudes y formas de comportamiento que debemos tener frente a las situaciones a las que nos enfrentamos. El aprendizaje del idioma en la infancia es un ejemplo esclarecedor, aprendemos el que nuestra madre y las personas cercanas hablan. Nadie nace hablando, adquirimos esta herramienta del entorno cercano e inmediato y al idioma hay que añadir otras formas de conducta y de pautas para relacionarnos con los demás. Siempre me he preguntado que habría ocurrido si cualquier de los que leen estas líneas, a los dos días de 
nacido, hubiera sido raptado por una pareja de chinos y vivido en ese país. Ciertamente seríamos notablemente diferentes a lo que somos ahora, comenzando por el manejo para comunicarnos con los demás del Mandarín o el Cantonés. La persona que ha llegado a su madurez y se ha configurado casi a plenitud, es deudor -para bien o para malen buena medida de la cultura en la que creció.

En una misma cultura, cada uno es distinto, porque hay otros componentes conformadores de la personalidad y porque dentro de la misma urdimbre de normas e ideas hay diversas posibilidades. Si creemos que tenemos algún espacio para ejercitar nuestra libertad, de las opciones que tomemos en las diversas situaciones dependerá nuestra realización. Volviendo a la afirmación hecha en líneas anteriores: tenemos capacidad para hacernos en el tiempo, pero circunscritos a elementos naturales y culturales que los entornos correspondientes nos ofrecen para resolver las necesidades o enfrentar los retos que se presentan en nuestras vidas. El esquimal de la región ártica y el habitante de la amazonía resuelven de manera diferente el problema de vivienda pues los condicionantes ecológicos son diversos, pero lo resuelven pues su creatividad les permite dar funciones específicas a los elementos que, precariamente en estos casos, la naturaleza les brinda. Distintas son las estrategias a las que recurre un devoto musulmán y un observante católico occidental para solucionar los problemas de cortejamiento y matrimonio que a determinada edad se le presentan.

Si para enfrentar situaciones y resolver problemas, quienes forman parte de la misma cultura deben soportar conflictos, cuando se incorporan -aunque sea temporalmente- a una cultura diferente la situación es más difícil. Comienza con la ausencia o limitaciones del manejo del lenguaje y siguen los desfases al recurrir a una forma de comportamiento propia de la cultura de la que se forma parte ante una situación, la misma que en la otra es desaprobada o causa desconcierto. El anecdotario jocoso de personas que actúan en otras culturas con patrones propios de la de ellos es abundante. El viejo aserto popular "a donde fueres haz lo que vieres" pretende prevenir 
a quienes deben enfrentar situaciones de esta índole para evitar que surjan conflictos no buscados o, en el más inocente de los casos, hacer el ridículo.

Si se trata de una cultura dominante en la que el etnocentrismo tiene dimensiones mayores, los conflictos se exacerban y llegan a dimensiones contrarias a la condición humana que justifican abusos e injusticias. La escena histórica en la que el Padre Valverde presenta a Atahualpa la Biblia y el Inca, luego de tenerla en sus manos por un momento, la arroja al suelo dando lugar a la arremetida de los españolas por haber "profanado" el libro sagrado, es trágicamente elocuente. Los incas no habían desarrollado la escritura y un libro era un objeto totalmente extraño, peor aún el carácter de sagrado que los de una cultura diferente lo atribuían Una visión antropológica que considera las diferencias culturales como una peculiaridad del ser humano y resta importancia a categorías que jerarquizan unas culturas con relación a las otras, da un paso fundamental para considerar que un humanismo entendido como comprensión y respeto a la humanidad, necesariamente tiene que fundamentarse en las diferencias culturales como esencial a la condición humana.

\section{Las culturas y los otros}

La Antropología Cultural comienza a ser considerada disciplina científica en la segunda mitad del siglo XIX, como una respuesta consciente de investigadores del mundo académico para tratar de explicarse y explicar a los demás las diferencias -desde el punto de vista occidental- en el comportamiento y las creencias de grupos humanos ubicados en áreas geográficas menos avanzadas tecnológicamente a las que llegaban en plan de conquista. Términos como primitivos eran usados para calificar a estos pueblos conquistados y sometidos, con la consiguiente connotación de inferioridad con respecto a los conquistadores. Si formas de comportamiento, ideas e instituciones existen como rasgos comunes y unificadores de una colectividad, razones internas deben existir para que se den y funcionen de esta manera. Conocerlas y explicarlas es la meta del 
antropólogo lo que supone esfuerzos para entender el orden partiendo de la cultura investigada y no de la del investigador.

La Antropología Cultural, aparece y se desarrolla en Occidente, fue un gran paso para superar el arrogante etnocentrismo de esta civilización que se arrastra desde la Grecia Clásica. Bárbaro en ese idioma significa extranjero, pero tuvo siempre la connotación peyorativa de persona carente de cultura, es decir que los otros conglomerados humanos que no participaban de las ideas y pautas de comportamiento de ellos eran, por definición incultos en el sentido tradicional del término; los romanos mantuvieron la misma actitud y la misma palabra para distinguir entre ellos, los civilizados, y los otros, los bárbaros. Los avances tecnológicos de la época de los grandes inventos y descubrimientos afianzaron esta posición y uno de los justificativos de los países europeos, tanto en América como en Oriente, para establecer sistemas de dominación sobre los conquistados, era la "carga" de civilizarlos. El desarrollo de la Revolución Industrial incrementó este complejo de superioridad. Si dentro del contexto humanista de empirismo y racionalismo el ser humano llega a su plenitud mediante el ejercicio de la razón que con el desarrollo de las ciencias y las técnicas da lugar a un dominio más eficiente de la realidad, los pueblos no occidentales que no habían llegado a esos niveles, eran inferiores o por lo menos se encontraban en una etapa inferior a la de los occidentales.

La primera escuela antropológica es la evolucionista que traslada a la cultura los principios biológicos de la evolución de las especies de Charles Darwin. Las diferencias entre las culturas se deben a que no todas se encuentran en el mismo nivel de evolución. La humanidad, en sus diferentes colectividades, ha recorrido y tiene que recorre tres etapas básicas: salvajismo, barbarie y civilización, encontrándose la occidental en la cúspide de este proceso y siendo juzgadas las otras a partir de este nivel de excelencia. Las que se encuentran en la etapa de salvajismo, con el transcurso del tiempo llegarán a la de civilización. No se trata de una diferencia esencial como la que existe entre los seres humanos y los animales, pues es cuestión de tiempo, pero de todos modos hay una condición de inferioridad en un 
momento dado.

La Antropología Cultural ha cambiado con el tiempo. La idea del antropólogo que deja los encantos de la civilización occidental para establecerse por un tiempo -más bien largo que corto- en una cultura retrasada -por lo menos tecnológicamente- para tratar de comprender sus principios internos que explican formas de comportamiento a primera vista extraños y escribir informes que se transforman en libros muy atractivos por la incursión que hace el lector en mundos exóticos, ha cambiado. Con los grandes avances de la comunicación física y del pensamiento, cada vez hay menos "pueblos primitivos" con estos "atractivos".

De un tiempo a esta parte, el interés de la Antropología Cultural se centra en el conocimiento de los otros, esto es de conglomerados humanos con pautas de conducta diferentes que obedecen a patrones culturales distintos de los ortodoxamente occidentales. Oscar Lewis ${ }^{4}$, en las décadas de los cincuenta y sesenta, realizó importantes estudios de colectividades humanas que forman parte de ciudades de indiscutible corte occidental, pero que tienen ideas, creencias y conductas notablemente diferentes sin que sean tribus de la Amazonía, Esquimales de Alaska, Bosquimanos del Africa subsariana o pueblos de las encantadoras islas de Oceanía.

Es también importante la incorporación a los grupos de antropólogos académicamente bien formados, de personas oriundas de países del tercer mundo como africanos, latinoamericanos o de la India. Aunque su formación académica se haya realizado con esquemas occidentales, las vivencias y experiencias de las culturas en las que se desarrollaron sus vidas no se borraron, surgiendo una visión del mundo occidental como del "otro diferente", tecnológicamente más avanzado, pero no superior y con defectos así considerados en sus culturas que para ellos son cualidades.

La conciencia de las diferencias culturales ha dejado los cenáculos académicos de la Antropología para convertirse en un interés cada vez más generalizado por conocer las culturas diferentes, por 
lo menos para satisfacer una curiosidad superficial como lo confirman programas de televisión dirigidos al gran público y espacios de prensa escrita; pero quedan otros espacios no del todo generalizados como la valoración de los otros y la valoración de lo diferente, pues la vida humana no se circunscribe al conocimiento, sino que en gran medida está vinculada a la valoración.

\section{Humanismo y valoración de lo diferente}

La dimensión axiológica influye con fuerza en la conformación de una visión humanista de la realidad. Es posible aceptar y hasta cierto punto entender culturas distintas a la occidental y a la vez rechazarlas porque no coinciden con la jerarquía de valores que nuestra cultura tiene. El desarrollo integral del ser humano no implica tan solo conocer mucho, sino aproximarse a la realización de los valores que considera como prioritarios. Dentro de una misma cultura -me referiré especialmente a la occidental, ya que en buena medida formamos parte de ella- es perfectamente posible que sus integrantes se realicen, es decir lleguen a niveles de excelencia, por distintos caminos culminando diferentes metas. Médicos, políticos, sacerdotes, artistas, empresarios, escritores, artesanos pueden alcanzar muy altos niveles de prestigio y satisfacción personal o en el ámbito del grupo al que pertenecen, pero una cultura se caracteriza por el aprecio colectivo a ciertos valores que están sobre aquellos de las áreas específicas en las que se desenvuelve la vida de las diferentes personas.

Un mismo hecho puede ser considerado un valor cuya realización sea encomiable en una cultura y merecer rechazo en otra e incluido en el listado de las prohibiciones. Tomar venganza en nuestra cultura es socialmente reprobado y el término vengativo es un reproche y no una alabanza. En la cultura Shuar, tomar venganza ante determinados hechos es una obligación, y hacerlo otorga al autor respetabilidad en su entorno social, abstenerse se interpreta como incumplimiento de una obligación con la consiguiente desaprobación de los integrantes de la colectividad. Lo que cuenta en 
nuestros días es superar la tendencia al rechazo de lo diferente en cuanto componentes estructuradores de otras culturas y aceptar esa diversidad como un elemento connatural a la riqueza y creatividad de la humanidad. El enfoque actual de la Antropología cultural se proyecta hacia esta actitud. Xavier Martín en su obra "La Antropología, Ciencia Humana, Ciencia Crítica" escribe:

"Desde la Antropología, los otros no necesitan ser pensados ni como pasado, ni como estúpidos, ni como hombres de escasa personalidad o como inferiores, en definitiva, como medio hombres; la Antropología es para ellos un mensaje liberador frente a cualquier intento de anexionarlos o reducirlos".

El acelerado avance tecnológico, especialmente en los medios de comunicación, ha hecho realidad lo que en nuestros días se conoce con el nombre de "globalización", que puede interpretarse como una tendencia creciente y generalizada a que en todos los rincones del planeta se adopten, por ser mejores, innovaciones tecnológicas con las consiguientes variaciones en formas de vida de los conglomerados humanos. Extremando esta tendencia, la aldea global día a día avanza para pasar de metáfora a realidad a causa de la uniformación en mengua de las diferencias identificatorias cada día más débiles. Esta visión parte de un planteamiento etnocéntrico occidental que considera como mejor lo generado, producido y estructurado por esta cultura. Queda fuera de discusión que en todas partes se tiende a incorporar los avances tecnológicos que arrancaron con la Revolución Industrial y que mejoran de alguna manera las condiciones de vida, pero no es correcto generalizar en el sentido de que otros elementos como religión, lengua, organización social y cosmovisiones tienen necesariamente que seguir el mismo camino.

Con el nombre de modernización se entiende en nuestros días los procesos de actualización tecnológica de los países y las colectividades, con los consiguientes cambios en formas y estilos de vida. La eficiencia de la informática para hacer frente a una serie de conflictos avanzados o comunes, la posibilidad de ágil acceso a información a través de internet, hacen que las diferentes culturas 
recurran a estos medios para agilitar la solución de una serie de problemas, sin que necesariamente se ocasione la pérdida o debilitamiento de la identidad. La destrucción de las torres gemelas de New York el 11 de Septiembre del 2001 atribuida al grupo fundamentalista islámico Al Qaida, liderado por Ben Laden, para lograr su objetivo largamente planificado con aterradora eficiencia, recurrió a tecnologías de punta en informática y comunicación. Según lo afirmado por el autor intelectual, esta nefasta acción tuvo por objeto defender la civilización islámica de las profanaciones de que era objeto por Estados Unidos al tener bases militares en Arabia Saudita, país sagrado según su interpretación. Sin discutir la solidez de esta fundamentación, en este caso se recurrió a tecnología de punta iniciada y desarrollada en Occidente para "defender" una civilización no occidental.

La globalización que avanza con rapidez en el tercer milenio posibilita un conocimiento más amplio y rico de las otras culturas Además de la información es posible tener contactos directos y experiencias vitales con ellas. La conciencia de "los otros" es cada vez menos lejana y exótica, es una vivencia cotidiana. Día a día dejan de ser seres extraños e inalcanzables -como los cuentos fantásticos infantiles- y la conciencia de que en nuestras vidas tenemos que contar con ellos se impone. En este contexto, la idea de ser humano en términos generales, y de humanismo como fundamento teórico de actitudes y comportamientos, ha cambiado y tiene que seguir cambiando.

Samuel Huntigton en su obra "El Choque de Civilizaciones" considera que superado o debilitado el enfrentamiento ideológico de los países del mundo, cobra cada vez más fuerza el enfrentamiento entre civilizaciones ${ }^{5}$, partiendo de un afán cada vez mayor de conocer la identidad y tener conciencia de formar parte de una cultura a la que se la valora y no de un gran mundo amorfo. Los países cada vez menos organizan sus políticas internacionales partiendo de la decisión de alinearse con potencias que preconizan ideologías, para hacerlo tomando en cuenta a que civilización pertenecen, o cuales son las más afines. Reproduzco algunas frases sobre el tema: 
"Mientras que un país podía evitar alinearse en la guerra fría, no puede ahora carecer de una identidad. La pregunta ¿Deque lado estás? Ha sido reemplazada por esta otra, mucho más fundamental?: ¿Quién eres?. Cada Estado debe tener unas respuesta, su identidad cultural, que define el lugar del Estado en la política global, sus amigos y sus enemigos.

Los años noventa han conocido la explosión de una crisis de identidad a escala planetaria. Casi en cualquier parte adonde se volviera la vista, la gente ha estado preguntándose ¿Quiénes somos?, ¿A dónde pertenecemos? Y ¿Quién no es de los nuestros?.

...La mayor relevancia de la identidad es en gran parte resultado de la modernización socio-económica, tanto en el plano individual, donde la dislocación y alienación crean la necesidad de identidades más significativas, como en el plano social , donde las mayores capacidades y poder de las sociedades no occidentales estimulan la revitalización de identidades y la cultura autóctonas.

...La identidad en cualquier plano -personal, tribal, racial o de civilización- solo se puede definir en relación a <otro>, una persona, tribu, raza o civilización diferente.

...Las fuentes de conflictos entre Estados y grupos de diferentes civilizaciones son, en gran medida, las que siempre han generado conflictos entre grupos de gente: el control de las personas, el territorio, la riqueza, los recursos y el poder relativo, que es la capacidad de imponer los propios valores, cultura e instituciones a otro grupo en comparación con la capacidad de dicho grupo para hacer eso con uno.

...Es humano odiar. Por definición y motivación, la gente necesita enemigos: competidores en los negocios, rivales en el rendimiento académico, opositores en política. ... La tendencia a un nosotros contra ellos es casi universal en la arena política. 
En el mundo contemporáneo es cada vez más probable que el <ellos> sea gente de una civilización diferente."(...1997....Barcelona, Paidós).

Los planteamientos de Huntington pueden conducir a enfrentamientos bélicos aterradores y a explosiones de violencia inusitadas como las del 11 de Septiembre de 2001, es posible evitar estas catástrofes si es que aceptamos, como algo positivo, que los "otros" constituyen manifestaciones propias de la creatividad humana y que las diferencias, lejos de ser amenazas, son enriquecedores complementos. Que el ser humano y la humanidad se encuentra mucho más allá de las fronteras de las culturas de que formamos parte, que podemos aprender mucho de los "otros" y que sólo tendremos una imagen mejorada de lo que somos, luego de un desprejuiciado conocimiento de los demás

\section{De vuelta al humanismo}

Un humanismo en consonancia con las condiciones de nuestros días debe partir del reconocimiento de las diferencias culturales como una manifestación de la riqueza de nuestra especie cuya creatividad no se limita a determinados planteamientos y caminos, puesto que el ser humano, poseedor del don de la creatividad, puede trasladar ideas y principios a hechos reales de muy diversas maneras.

Una comprensión cabal de estas diferencias no puede lograrse partiendo de patrones estructuradores de la cultura de la que formamos parte, si no de aquellos que conformaron a los "otros" conglomerados humanos. Tenemos capacidad suficiente para liberarnos temporalmente de nuestras estructuras interiores y entender otras realidades desde sus veneros.

Está bien que cada persona se sienta parte de su cultura, se integre a ella y busque realizarse dentro de sus pautas e ideas, pero no tiene sentido que este ordenamiento del comportamiento esté 
contaminado con posiciones que no respeten a las otras culturas por considerar que carecen de algunos componentes de aquella de la que formamos parte y a los que se les da validez universal. Hay principios universales de planteamientos culturales, pero la manera como se concretan en cada cultura es diferente y tienen legitimidad en cada una de ellas.

Si aceptamos la capacidad de hacerse diferentes de los grupos humanos, un auténtico humanismo no debe limitarse a conocer lo distinto y comprenderlo como una alternativa a las múltiples posibilidades de la creatividad humana. Es necesario valorar lo que los otros han creado partiendo de su "lógica interna" que nos llevará a descubrir no sólo realizaciones distintas sino limitaciones y carencias de nuestra propia cultura. El factor axiológico es esencial en las estructuras de las culturas, no es suficiente para una comprensión cultural de los "otros", entender los rasgos distintos tan sólo desde la mente, hay también que tener una idea clara de la manera como cada cultura valora y jerarquiza a sus componentes.

La UNESCO en su informe 2000 sobre educación considera que uno de los principales objetivos educativos del tercer milenio consiste en enseñar a vivir con los "otros", es decir a desarrollar nuestras mentes y afectividades para organizar y planificar la vida en un medio en el que la presencia de lo diferente es cotidiana, sin que a priori consideremos que por ser distintos son inferiores o fuentes de conflictos, sino al contrario, que contribuyen al crecimiento integral de las personas y las colectividades.

Emparedados, aislados en nuestra cultura, el conocimiento de nosotros mismos es limitado e incompleto; al coexistir con los "otros" y esforzarnos por conocerlos descubriremos una serie de rasgos nuestros de los que no teníamos conciencia pues no se mostraban con evidencia por ausencia de referentes distintos. El conocimiento del otro debe partir de buena fe en el sentido de apertura mental y anímica que nos libere de la tendencia a buscar defectos que nos consoliden como los únicos acertados. 
Si más que con la realidad en sí organizamos nuestras ideas y conductas con las percepciones de esa realidad (la realidad en mi), los prejuicios contribuyen a deformar grotescamente las percepciones y los juicios de ellas derivados. El prejuicio proviene de falta de conocimiento adecuado de lo otro a causa de ideas que, sin la debida evidencia, han sido generadas o aceptadas sin sentido crítico. En las condiciones en que actualmente vivimos, el acceso directo sin intermediarios a los otros nos posibilita disminuir sustancialmente los prejuicios logrando un mejor conocimiento y valoración del ser humano en sus múltiples diversidades.

Cualquier forma de dogmatismo, al "convertir" en verdades lo que son opiniones o conjuntos de opiniones, es la negación del humanismo que supone respuestas distintas a distintos planteamientos como connatural a la condición humana. Los dogmatismos parten de la inseguridad y el temor que determinadas personas tienen de hacer frente a la realidad. La aceptación como únicas de tales o cuales "verdades" genera una seguridad ficticia ya que reduce la diversidad de las personas y los conglomerados humanos a espacios mínimos. Ante el temor de hacer frente a la diversidad, la mejor política es la de la avestruz al ocultar la cabeza en un agujero cono lo que se da por eliminada la amenaza externa. Los dogmáticos ocultan sus cabezas en las estrecheces de sus dogmas y, negándose a considerar siquiera cualquier alternativa, eliminan el temor a su existencia.

Una forma manifiesta o a veces velada de dogmatismo es el etnocentrismo que se niega a considerar siquiera la posibilidad de validez de componentes de otras culturas que no coincidan con los de aquellos de las que se forma parte, peor aún si los contradicen. La meta a corto, mediano y largo plazo de la Antropología Cultural es superar el etnocentrismo para comprender a las otras culturas desde sus planteamientos. La Antropología Cultural es, entonces, la posición y la actitud más adecuada para entender al ser humano como diverso, aceptarlo y respetarlo eliminando cualquier intención de negar o menospreciar lo diferente. 
Personalmente considero que sería trágico para el ser humano "encontrar la verdad" ya que desaparecería su condición de permanente buscador y la curiosidad, como elemento dinámico de su razón ya no tendría razón de ser. Sin plantear un relativismo absoluto, y sin afirmar de manera contundente que cada cultura tiene su verdad o sus verdades, pienso que cada una cuenta con sus "caminos" para aproximarse. Una mirada al pasado nos muestra que visiones de muchos aspectos de la realidad que se las daba por evidentes hoy se las considera falsas, incompletas y a veces absurdas. Si consideramos que cada época tuvo sus "verdades", no quiere decir que la verdad no existe, sino que las etapas para su aproximación han sido superadas. Si decimos que cada cultura tiene sus "verdades", no afirmamos que ésta no exista sino que las formas de aproximación son diferentes.

El humanismo parte de la idea que cada época y cada cultura tiene del hombre ideal de allí que de tiempo en tiempo se habla de "hacer un hombre nuevo", en el sentido de adecuado a los nuevos planteamientos de la cambiante sociedad. Si en los albores del tercer milenio hablamos de un "hombre nuevo", tiene éste que fundamentarse en la aceptación, respeto y satisfacción de su diversidad, en otras palabras de los planteamientos con que nació la Antropología Cultural en la segunda mitad del siglo XIX y que se han robustecido y ampliado a lo largo de los años: la comprensión de otras culturas

NOTAS

1. Las Tres Fuentes de la Reflexión Etnológica

2. Marinov, en su obra Más Platón y Menos Prozac nos muestra como en el mundo contemporáneo el filósofo puede ser un consejero que ayuda a clientes a solucionar problemas de la vida con una visión diferente del sicólogo y el siquiatra. Hay cada vez más consultorios de esta índole. 
3. En su obra "El Pensamiento Moderno y la Idea del Hombre, El Dr. Francisco Alvarez González escribe: Racionalistas y Empiristas estaban completamente de acuerdo. Si los primeros fundamentaban la igualdad en la identidad de una especie de razón supraindividual, la misma para todos, los segundos buscaban apoyo para esta creencia en el supuesto básico de su teoría gnoseológica: la ausencia de ideas innatas y el carácter por igual vacío de toda conciencia al nacer que le hace semejante a un papel en blanco

4. De las obras escritas por Lewis, es muy interesante "Antropología de la Pobreza" en la que analiza la forma de vida de cinco familias procedentes del mismo pueblo que viven en la ciudad de México generándose un entorno cultural en el que la pobreza y hábitos del campo coexisten con la opulencia de barrios de grandes ciudades

5. Para Huntington los conceptos civilización y cultura tienen mucho en común; sintetiza su idea cuando afirma que "civilización es una cultura con mayúscula".

\section{BIBLIOGRAFIA CONSULTADA}

Alvarez González, Francisco

El Pensamiento Moderno y la Ideal del Hombre, 1988, Editorial Universidad Nacional a Distancia, San José, Costa Rica.

Delors Jacques

La Educación Encierra un Tesoro, 1996, Ediciones UNESCO, México D.F.

Eriksen, Thomas Hylland

Ethnicity \& Nationalism, 1993, Pluto Press, London.

Hall, Edward

Beyond Culture, 1976, Anchor Books, New York.

Huntington Samuel

El Choque de Culturas, 2001, Paidós, Barcelona.

Levi-Strausse, Claude

Las Tres Fuentes de la Reflexión Etnológica, 1975 EUDEBA, Buenos Aires.

San Martín, Javier

La Antropología, Ciencia Humana, Ciencia Crítica, 1992, Montesinos, Barcelona. 